The long shadow of childhood disadvantage on lifelong health: getting worse over time?

\title{
Maria Melchior
}

Sorbonne Université, INSERM, Institut Pierre Louis d'Epidémiologie et de Santé Publique, Department of Social Epidemiology, 75012 Paris, France

Correspondence to: Dr Maria Melchior, Department of Social Epidemiology, IPLESP, INSERM U1136, Faculté de Médecine Saint-Antoine, 75012 Paris, France (e-mail: maria.melchior@inserm.fr)

Social inequalities in health and their early life origins have been extensively documented. Although the complex direct and intermediate mechanisms linking early life disadvantage to later health are not yet fully understood, new findings on biological markers distinctly related with early life experiences suggest a causal relation. In their paper, Fuller-Rowell et al step back to examine the role of childhood disadvantage in the United States in different periods, and observe that the relationship with later health seems to have strengthened over time. The main explanation the authors bring up has to do with increased income segregation and changes in labour market composition which limit opportunities for persons with low educational attainment. In other words, while the rich get richer, the poor get poorer, the middle class shrinks, and there are fewer interactions across different socioeconomic groups and the social ladder is blocked. Other evidence suggests that investments in children, through early education and academic support programs, could help reduce the consequences of childhood disadvantage on long-term health. 
In a new study based on data from the representative Midlife in the United States study (MIDUS) conducted in 1995 and 2012 among respectively 7,108 and 3,577 adults aged on average 45-48 years, Fuller-Rowell et al report that a composite index of childhood socioeconomic disadvantage is associated with indicators of health including a higher body mass index, waist circumference, chronic conditions, functional limitations and self-rated health (1). Importantly, the authors report stronger associations between childhood socioeconomic disadvantage among participants interviewed in 2012 than those who participated in 1995, suggesting a steepening of socioeconomic inequalities in health over time with an approximate doubling of the effect between the two study waves. While race/ethnicity does not appear to modify the strength of the association between childhood socioeconomic disadvantage and adult health, there is an interaction with sex such that women appear more vulnerable to the consequences of early socioeconomic difficulties.

These findings add to a growing body of evidence indicating that childhood socioeconomic circumstances are associated with long-term health patterns (2-4), including increased cardiovascular risk (5) and biological markers of inflammation $(6,7)$. In addition, growing up in disadvantage has also been associated with later mental health difficulties including depression (8-10), anxiety (11), autism (12) and psychosis (13).

Fuller-Rowell et al. put much emphasis in the discussion of their findings on the rise of income inequality in the United States since the 1990s, which results in the concentration of wealth on the one hand and poverty on the other hand, and limits labour market opportunities for those who are least qualified or reside in areas where employment is scarce. It is important to bear in mind that one of the reasons why childhood socioeconomic position influences long-term health is because it shapes educational and employment opportunities (9). For instance, a recent study estimated that $10-20 \%$ of the relation between childhood socioeconomic position and mid-life adiposity is statistically explained by low educational attainment (14). Research showing that the accumulation of disadvantage over the lifecourse is more strongly associated with poor health in adulthood than more transient socioeconomic difficulties is consistent with this interpretation $(11,15)$.

However, it may also be that the experience of adversity in childhood has direct negative effects on individuals' biology because of a heightened probability of experiencing chronic stress (ex. negative life events, violence or instability). Early research in this area was primarily based on the hypothesis that growing up in disadvantage is related to 'toxic stress' (16), which results in the circulation of high levels of stress hormones that can be damaging to multiple tissues in the body and brain (17). Recently, researchers have turned to the quest for epigenetic marks which could sign exposure to disadvantage and condition biological functioning $(18,19)$. The important question now is whether these biological mechanisms can be modified by individuals' personal characteristics (ex. certain personality traits, social support received from other persons)(20) or by improvements in socioeconomic circumstances (21). Future research using longitudinal data collected in large-size samples and taking into consideration individual as well as family and neighborhood characteristics should help better understand the way in which socioeconomic inequalities in childhood translate to health disadvantage in adult life. 
Still, the body of evidence showing that childhood disadvantage bears negative consequences on individuals' long-term life opportunities and health is solid enough to suggest that protecting families with children from socioeconomic difficulties and their consequences should be a public health priority. Fuller-Rowell et al imply that decreasing income inequalities through economic policies such as taxation could be a solution. Additionally, as shown by a recent meta-analysis of randomized controlled trials, various kinds of social policies, particularly those aiming to improve early life and educational opportunities, have also been shown to have a positive impact (22). Once again, as FullerRowell et al remind us, determinants of lifecourse health largely lay outside of the realm of medicine and health science, and should be addressed in an intersectoral and long-term way, by including approaches such as Health in All Policies (23).

\section{References}

1. Fuller-Rowell TE, Nichols OI, Jokela M, Kim ES, Yildrim ED, Ryff CD. The changing landscape of health opportunity in the United States: increases in the strenght of association between childhood socioeconomic disadvantage and adult health between the 1990s and the 2010s. American Journal of Epidemiology. 2021;XX(XX):XX.

2. Poulton R, Caspi A, Milne BJ, Thompson WM, Taylor A, Sears MR, et al. Association between children's experience of socioeconomic disadvantage and adult health: a life-course study. The Lancet. 2002;360:1640-5.

3. Galobardes B, Lynch JW, Davey SG. Childhood socioeconomic circumstances and cause-specific mortality in adulthood: systematic review and interpretation. Epidemiological Reviews. 2004;26:7-21.:7-21.

4. Birnie K, Cooper R, Martin RM, Kuh D, Sayer AA, Alvarado BE, et al. Childhood socioeconomic position and objectively measured physical capability levels in adulthood: a systematic review and meta-analysis. PLoS One. 2011;6(1):e15564.

5. Galobardes B, Smith GD, Lynch JW. Systematic review of the influence of childhood socioeconomic circumstances on risk for cardiovascular disease in adulthood. Annals of Epidemiology. 2006;16(2):91-104.

6. Liu RS, Aiello AE, Mensah FK, Gasser CE, Rueb K, Cordell B, et al. Socioeconomic status in childhood and $C$ reactive protein in adulthood: a systematic review and metaanalysis. Journal of Epidemiology and Community Health. 2017;71(8):817-26.

7. Milaniak I, Jaffee SR. Childhood socioeconomic status and inflammation: A systematic review and meta-analysis. Brain Behavior and Immunity. 2019;78:161-76.

8. Gilman SE, Kawachi I, Fitzmaurice GM, Buka SL. Socioeconomic status in childhood and the lifetime risk of major depression. International Journal of Epidemiology.

2002;31(2):359-67.

9. Melchior M, Moffitt TE, Milne BJ, Poulton R, Caspi A. Why do children from socioeconomically-disadvantaged families suffer from poor health when they reach adulthood? A lifecourse study. American Journal of Epidemiology. 2007;166(8):966-74. 10. Melchior M, Ziad A, Courtin E, Goldberg M, Zins M, van der Waerden J. Intergenerational Socioeconomic Mobility and Adult Depression: The CONSTANCES Study. American Journal of Epidemiology. 2018;187(2):260-9.

11. Morrissey K, Kinderman P. The impact of childhood socioeconomic status on depression and anxiety in adult life: Testing the accumulation, critical period and social mobility hypotheses. SSM Population Health. 2020;11:100576. 
12. Rai D, Lewis G, Lundberg M, Araya R, Svensson A, Dalman C, et al. Parental socioeconomic status and risk of offspring autism spectrum disorders in a Swedish population-based study. Journal of the American Academy of Child and Adolescent Psychiatry. 2012;51(5):467-76.

13. Wicks S, Hjern A, Gunnell D, Lewis G, Dalman C. Social adversity in childhood and the risk of developing psychosis: a national cohort study. American Journal of Psychiatry. 2005;162(9):1652-7.

14. Gilman SE, Huang YT, Jimenez MP, Agha G, Chu SH, Eaton CB, et al. Early life disadvantage and adult adiposity: tests of sensitive periods during childhood and behavioural mediation in adulthood. International Journal of Epidemiology. 2019;48(1):98107.

15. Lopes JAS, Giatti L, Griep RH, Lopes AA, Matos SMA, Chor D, et al. Life course socioeconomic position, intergenerational social mobility, and hypertension incidence in ELSA-Brasil. American Journal of Hypertension. [In Press]

16. Shonkoff JP, Boyce WT, McEwen BS. Neuroscience, molecular biology, and the childhood roots of health disparities: building a new framework for health promotion and disease prevention. Journal of the American Medical Association. 2009;301(21):2252-9.

17. McEwen BS. Brain on stress: how the social environment gets under the skin. Proceedings of the National Academy of Sciences. 2012;109 Suppl 2(Suppl 2):17180-5. 18. Nasca C, Bigio B, Zelli D, Nicoletti F, McEwen BS. Mind the gap: glucocorticoids modulate hippocampal glutamate tone underlying individual differences in stress susceptibility. Molecular Psychiatry. 2015;20(6):755-63.

19. Carmeli C, Kutalik Z, Mishra PP, Porcu E, Delpierre C, Delaneau O, et al. Gene regulation contributes to explain the impact of early life socioeconomic disadvantage on adult inflammatory levels in two cohort studies. Science Reports. 2021;11(1):3100.

20. Non AL, Román JC, Clausing ES, Gilman SE, Loucks EB, Buka SL, et al. Optimism and social support predict healthier adult behaviors despite socially disadvantaged childhoods. International Journal of Behavioral Medicine. 2020;27(2):200-12.

21. Castagne R, Delpierre C, Kelly-Irving M, Campanella G, Guida F, Krogh V, et al. A life course approach to explore the biological embedding of socioeconomic position and social mobility through circulating inflammatory markers. Scientific Reports. 2016;6:25170.

22. Courtin E, Kim S, Song S, Yu W, Muennig P. Can social policies improve health? A systematic review and meta-analysis of 38 randomized trials. Milbank Quarterly. 2020;98(2):297-371.

23. Baum F, Lawless A, Delany T, Macdougall C, Williams C, Broderick D, et al. Evaluation of health in all policies: concept, theory and application. Health Promotion International. 2014;29 Suppl 1:i130-42. 